\title{
Psychotic experiences in patients with obsessive compulsive disorder. A cross sectional clinical study
}

\author{
MOHAMMAD ALI GHOREISHIZADEH M.D ${ }^{1}$, SEPIDEH HERIZCHI M.D², SARA FARHANG M.D ${ }^{3}$, SANAZ VALAEEM.D ${ }^{4}$ \\ ${ }_{1}$ Professor of psychiatry, Research Center of Psychiatry and Behavioral Sciences, Tabriz University of Medical Sciences, Tabriz, Iran. \\ ${ }^{2}$ Associate Professor of psychiatry, Research Center of Psychiatry and Behavioral Sciences, Tabriz University of Medical Sciences, Tabriz, \\ Iran. \\ ${ }^{3}$ Assistant Professor of psychiatry, Research Center of Psychiatry and Behavioral Sciences, Tabriz University of Medical Sciences, Tabriz, \\ Iran. University of Groningen, University medical center Groningen, University Center for Psychiatry, Rob Giel research center, Groningen. \\ The Netherlands. \\ ${ }^{4}$ Psychiatrist, Research center of psychiatry and behavioral sciences Tabriz University of Medical Sciences, Tabriz, Iran. \\ For correspondence: Razi Hospital, Elgoli road, Tabriz, East Azerbaijan, Iran. Tel/Fax:+984133803353. \\ sherizchi@gmail.com, herizchis@tbzmed.ac.ir
}

\begin{abstract}
Background: Obsessive-compulsive disorder (OCD) is associated with heterogeneous and diverse symptoms. A diagnosis is challenging when patients experience psychotic symptoms. This study aimed to evaluate the pattern of psychotic symptoms in patients with OCD.

Methods: Using semi-structured clinical interviews, 185 patients meeting the DSM-IV diagnostic criteria for OCD were selected. The Yale-Brown Obsessive Compulsive Scale (Y-BOCS) and the Scale for the Assessment of Positive/Negative Symptoms (SAPS/SANS) were used to measure the OCD severity and insight levels and the pattern of psychotic symptoms, respectively. Characteristics of patients with and without psychotic experiences were compared.

Results: A total of 38 patients (20.5\%) displayed psychotic symptoms. Delusions were observed in $63.2 \%$ of these patients, while in $13.2 \%$ of them, delusions were accompanied with negative symptoms. Men, those aged between 18 and 34 years, less educated, and singles displayed significantly higher rates of psychotic symptoms. The mean Y-BOCS score $(26.42 \pm 5.07)$ was significantly higher in patients with psychotic symptoms than in those without (24.97 \pm 6.38$)$.

Conclusion: The results showed that in OCD patients, psychotic symptoms are more common in young $(<30$ years), single, less educated, and those with severe OCD.

Keywords: obsessive-compulsive disorder; psychosis; insight.
\end{abstract}

\section{INTRODUCTION}

What is "already known" in this topic:

There was few studies of psychotic symptoms co morbidity in the patients with obsessive compulsive disorder.

Psychotic symptoms are not rare in the patients with obsessive compulsive disorder.

What this article adds:

In the assessment and of the patients with obsessive compulsive disorder existence of Psychotic symptoms should be more noticed.

Prevalence of obsessive-compulsive disorder (OCD) as one of the most debilitating disorders, is $2-3 \%$ in the general population. $(\underline{1}, \underline{2})$

This disorder affects $10 \%$ of outpatients in public and private psychiatric clinics, and OCD is the fourth most common psychiatric illness. $(\underline{1}, \underline{2})$

Epidemiological studies conducted in Asia, Europe, and Africa indicate that this disorder is not associated with culture and geography, and comparable prevalence rates have been reported in these studies; and some symptoms may be influenced by environmental factors. ( $\underline{3})$

OCD tends to be a chronic condition, and treatment responses are not always good. Almost half of patients with OCD do not respond to initial treatment and their symptoms exacerbate over time. It results in severe disability and discomfort, and devastating effects on educational, occupational, and social functions. However, these patients should not be disappointed about the treatment outcomes (4).
No specific biomarker has been found so far for diagnosing $O C D$, and the overlap with other mental conditions can be clinically challenging, psychotic disorders in particular. $(\underline{5}, \underline{6})$

$O C D$ is increasingly viewed as a neuropsychiatric disorder that is mediated by specific neurocircuits such as anterior cingulate, orbitofrontal cortex, and striatum. One hypothesis explains that cortico-striatal-thalamiccortical(CSTS) circuitry plays a particularly important role in mediating OCD, with activation or inhibition of different components of this circuitry. Most studies suggest that a range of neurotransmitter system contribute to OCD, including serotonergic, dopaminergic,glutamatergic, and GABAergic systems. Most resent studies indicate the important role of glutamatergic system with evidence that some glutamatergic agents may be useful in this condition(2). Sometimes this heterogeneous and diverse condition is easily diagnosed (e.g. washing and checking); however, some patients with OCD lack insight, and their obsessive thoughts turn into delusions; in other words, these patents display psychotic symptoms. Therefore, it is difficult to distinguish OCD from psychosis and schizophrenia. In psychiatric literature, this disorder was referred to as Complicated OCD, Psychotic OCD, Delusional OCD, and Schizophrenic OCD, up until DSM-IV classified this type as a subgroup with a poor insight $(\underline{7}, \underline{8})$.

In 2013 , some changes were made to the diagnosis, classification, and definition of OCD in DSM-5. It was removed from the anxiety disorders category and placed in 
the specific category of obsessive-compulsive and related disorders (OCRDs). DSM-5 extended the insight specifier and categorized patients with OCD into three levels based on the level of insight (i.e. good insight, poor insight, and no insight). The latest version of the International Classification of Diseases (ICD-11) also classified OCD in a separate category, and accepted subcategory with no insight, or delusional ( $\underline{9})$.

Describing this specific subgroup has eliminated all previous ambiguities, challenges, and mistakes, and has developed a new attitude towards diagnosis and treatment of OCD. New studies have shown a $4-14 \%$ prevalence rate among Patients with OCD. $(\underline{10}, \underline{11})$

Considering the clinical importance, high prevalence, and high disability rates, new diagnostic and therapeutic approaches, and lack of previous studies in different cultures about delusional OCD, this study was designed to determine the frequency of this condition, specify various types of delusions and other psychotic experiences in patients with OCD, and identify the demographic and clinical characteristics of these patients. Previous studies have mainly focused on delusion and lack of insight; however, this study focused on other positive or negative psychotic symptoms too.

\section{METHODS}

\section{Procedure}

This study was performed in outpatient clinics of Tabriz university of Medical Sciences. Patients aged 18-65 years with a diagnosis of OCD based on diagnostic criteria of Diagnostic and Statistical Manual of Mental Disorders (12) were included after giving written informed consent.

\section{Inclusion criteria}

- $\quad$ Age range of 18-65 years

- Compliance with the DSM-IV diagnostic criteria for OCD

- Willingness and consent to participate in the study

Exclusion criteria

- $\quad$ Suffering from another axis I psychiatric illness based on the SCID for DSM-IV (i.e. rejecting any comorbidity with other psychiatric disorders)

- Mental retardation

- Drug abuse

- Medical illness

- Neurological disease

\footnotetext{
Measures

1.Yale-Brown Obsessive-Compulsive Scale (Y-BOCS)

This standardized scale has been applied in many studies before. It measures the severity of OCD symptoms. In this 10-item scale, 5 items measure obsessive thoughts and 5 others measure compulsory actions. All items are scored from 0 (no symptom) to 4 (severe symptom). In a study on 40 Patients with OCD, an inter-rater reliability of 0.98 , and a mean internal consistency of 0.89 were obtained for $Y$ BOCS. The convergence validity between $Y$-BOCS and the Clinical Global Impression of Obsessive Compulsive Syndrome (CGIOCS) in the baseline has been reported to be $0.97(\underline{12}, \underline{13})$.

2. The Scale for the Assessment of Positive/Negative Symptoms (SAPS/SANS)
}

In the late 1980s, this scale was designed by adding additional items to the Brief Psychiatric Rating Scale (BPRS) and providing detailed examples for each item in order to overcome tangible deficiencies in the assessment of positive and negative symptoms of schizophrenia and other psychiatric disorders. High reliability and excellent internal consistency and inter-rater reliability values have been reported for the scale in various studies. The validity of the scale has also been acceptable. Due to its high reliability and good coverage of positive and negative symptoms, it is an excellent tool for assessing positive and negative symptoms in schizophrenia and other psychiatric disorders. (14)

\section{The Structured Clinical Interview for DSM-IV (SCID)}

This tool is used for diagnosing other psychiatric disorders in patients (examining comorbidities). This semi-structured interview gives some diagnoses based on the DSM-IV. It has been used more than any other standard diagnostic interview in psychiatric studies $(\underline{15}, \underline{16})$.

Using intercultural research approach, translated this tool into Farsi and measured its validity in a multicenter trial. Kappa, diagnostic agreement, sensitivity, and specificity indexes were used for measuring the validity of this scale. The obtained Kappa values were above 0.4 for all diagnoses (except for the total anxiety disorders). The specificity percentages were above $85 \%$ for all diagnoses (and above $90 \%$ for half of them), which indicates the desired specificity of this tool $(\underline{16}, \underline{17})$.

4. The researcher-made questionnaire (used for collecting relevant demographic and clinical data), $(12,16)$.

\section{Ethics}

This study was approved by the ethics committee of Tabriz University of Medical Sciences. Ethical code is 94/3- 5/7.

All patients completed informed consent and all data was secret.

\section{RESULTS}

A total of 185 patients meeting the inclusion criteria for OCD were selected and enrolled. In this study, 38 patients $(20.5 \%)$ were presented with poor insight to symptoms, while 147 patients (79.5\%) had a good insight and acknowledged the un-realistic nature of their symptoms.

The pattern of psychotic experiences in participants is shown in Table 1 . Near to $25 \%$ of patients have had psychotic experiences. Delusion was the most common psychotic symptom in these patients. Paranoid delusions $(29.2 \%)$, delusions of reference $(19.5 \%)$, guilt $(17.1 \%)$, sexual (14.6\%) and somatic (7.3), passivity (7.3\%), and jealousy delusion $(4.8 \%)$ were the most common delusions, respectively. However, other symptoms including circumstantiality, negative symptoms, such as social isolation, poor hygiene, and passivity were observed alone or along with various delusions. Some patients displayed more than one psychotic symptoms.

Table 2 shows demographic and clinical characteristics of patients with and without psychotic experiences. As described in table 2, experience of psychotic symptoms is significantly higher in men compared to women $(p=0.032)$. It is also more common in patients aged between 18 and 30 years $(p=0.001)$. The rate was not related to the place of residence; however, less educated patients (under high school diploma) $(p=0.043)$ 
and singles $(p=0.000)$ displayed significantly more psychotic symptoms. There was no significant difference between those with and without psychotic symptoms in terms of family history.

The mean age of onset of OCD was $22.05 \pm 6.67$ years $(\min =13 ; \max =41)$ in patients with psychotic symptoms that was significantly higher compared to those without $(26.83 \pm 8.28$ years, range:13-59, $p=0.001)$. the mean duration of OCD was not different between the two groups and was $4.42 \pm 4.31$ years in those with psychotic symptoms, and $4.59 \pm 3.57$ years in those without $(p=0.8)$.

The mean Y-BOCS score was $26.42 \pm 5.07$ ( $\min =14$; $\max =36$ ) in patients with psychotic symptoms, while, it was significantly lower in those without psychotic symptoms (24.97 \pm 6.38 , range $10-40, p=0.029)$.

Table 1: Pattern of psychotic symptoms in the patients with OCD

\begin{tabular}{|l|l|l|}
\hline The pattern & Frequency & Percentage \\
\hline Only delusion & 24 patients & $(63.2 \%)$ \\
\hline Only hallucination & 1 patient & $(2.6 \%)$ \\
\hline Only formal thought disorders & 2 patients & $(5.3 \%)$ \\
\hline Only negative symptoms & 3 patients & $(7.9 \%)$ \\
\hline Delusion with hallucination and negative symptoms & 2 patients & $(5.3 \%)$ \\
\hline Delusion with negative symptoms & 5 patients & $(13.2 \%)$ \\
\hline Delusion with hallucination & 3 patients & $(7.9 \%)$ \\
\hline
\end{tabular}

Table 2: Demographic and clinical characteristics of patients with OCD with and without psychotic symptoms.

\begin{tabular}{|c|c|c|c|c|}
\hline & & $\begin{array}{l}\text { With psychotic } \\
\text { symptoms } \\
\mathrm{N}=38\end{array}$ & $\begin{array}{l}\text { No psychotic } \\
\text { symptoms } \\
\mathrm{N}=174\end{array}$ & P-Value \\
\hline \multirow[t]{2}{*}{ Gender } & Male & $21(55.3 \%)$ & $54(36.7 \%)$ & \multirow{2}{*}{0.038} \\
\hline & Female & 17 (44.7\%) & $93(63.3 \%)$ & \\
\hline \multirow[t]{3}{*}{ Age } & $18-30$ & $60(68.2 \%)$ & $28(73.7 \%)$ & \multirow{3}{*}{0.001} \\
\hline & $31-40$ & $73(49.7 \%)$ & $9(23.7 \%)$ & \\
\hline & $\leq 41$ & $14(9.5 \%)$ & $1(2.6 \%)$ & \\
\hline \multirow[t]{4}{*}{ Qualifications } & high school diploma & $21(55.3 \%)$ & $50(34 \%)$ & \multirow{4}{*}{0.043} \\
\hline & High school Diploma & $7(18.4 \%)$ & $51(34.7 \%)$ & \\
\hline & Associate Degree & $0(0 \%)$ & $8(5.4 \%)$ & \\
\hline & Bachelor and higher & $10(20.8 \%)$ & $38(25.6 \%)$ & \\
\hline \multirow[t]{2}{*}{ Residence } & Urban & $29(77.3 \%)$ & $124(84.4 \%)$ & \multirow{2}{*}{0.243} \\
\hline & Rural & $9(22.7 \%)$ & $23(15.6 \%)$ & \\
\hline \multirow[t]{3}{*}{ Marital status } & Married & $10(26.3 \%)$ & $100(68 \%)$ & \multirow{3}{*}{0.01} \\
\hline & Single & $27(71.1 \%)$ & $44(62 \%)$ & \\
\hline & Divorced & $1(2.6 \%)$ & $3(2 \%)$ & \\
\hline \multirow[t]{2}{*}{ Family history } & Positive & $14(36.8 \%)$ & $69(46.9 \%)$ & \multirow{2}{*}{0.265} \\
\hline & Negative & $24(63.2 \%)$ & $78(53.1 \%)$ & \\
\hline \multirow[t]{3}{*}{ Severity } & Mild & $1(2.6 \%)$ & $8(5.4 \%)$ & \multirow{3}{*}{0.013} \\
\hline & Moderate & $9(23.7 \%)$ & $70(47.6 \%)$ & \\
\hline & Severe & $8(73.7 \%)$ & $69(46.9 \%)$ & \\
\hline
\end{tabular}

\section{DISCUSSION}

An overlap between OCD and schizophrenia spectrum includes atypical presentations of OCD, OCD with no insight, $\mathrm{OC}$ symptoms in patients with psychosis and effect of antipsychotics on OCD symptoms (18). This study reports prevalence and indicators of different psychotic symptoms in patients with OCD.

The relationship between OCD and psychosis was first discussed about 80 years ago. According to recent studies, there might be no boundary between obsessive thoughts and delusions, as some patients with OCD may lose their insight, and their obsessive thoughts may turn into delusions $(\underline{19}, \underline{20})$. The strength of obsessive thoughts in patients with OCD, might range from overvalued ideas to delusion. Some studies have proposed that OCD might change to psychotic disorder over time. $(\underline{21}, \underline{22})$
Patients with poor insight tend to have more severe symptoms and responded less to medications. (23)

In addition, patients with OCD who have different type of hallucinations, lack insight (24), which is in line with results of present study, that all patients with psychotic symptoms lacked insight.

Population based studies have reported a high odds of having psychotic symptoms, mostly delusions patients with $\operatorname{OCD}(\underline{13})$ that was replicated in the present study and delusion (63\%) was the most common psychotic symptom. In the present study, the majority of the patients with psychotic signs and symptoms (35 patients, 92.1\%) displayed positive symptoms, and only 8 patients $(21.1 \%)$ displayed negative symptoms. Though negative symptoms have not been perceived in all of studies, there are reports that OCD patients with psychotic symptoms mostly display negative symptoms (2) $)$. 
There is a complex relation between OCD and psychosis, and their phenotype predict each other at different levels (24). Presence of psychotic symptoms in patients with OCD may be caused by comorbid emotional or psychiatric disorders $(\underline{25}, \underline{26})$. For example, the comorbidity between OCD and depression is very common as well as schizotypal and obsessive-compulsive personality disorder However, in this study, patients with another psychiatric disorders were excluded. On the other hand, OCD in also common patients with psychotic disorders. (27)

OCD symptoms are also highly prevalent in patients with bipolar, bulimia, and Tourette disorders; therefore, the diagnosis might be challenging and presence of other diagnostic criteria have an important role $(\underline{28}, \underline{29})$.

Previous studies, have reported a specific subgroup of OCD with no insight and delusional thoughts with a rate of $4-14 \%(\underline{30})$. For example, $14 \%$ of the patients studied by Eisen et al. (31) and $17 \%$ of those studied by De Haan et al. (mostly male patients) displayed psychotic symptoms (26). In the present study, $20.5 \%$ of the OCD patients displayed psychotic symptoms, and these symptoms were significantly higher in men, which is consistent with the above study. In the study of Adam et al., $40 \%$ of patients had delusions and hallucinations. (32)

Difference in method of sampling, as well as cultural or genetic factors might explain this difference. Although there have been several similarities. Eisen et al. found that psychotic symptoms mainly appear in younger people. (33), which is consistent with the present results too. In the present study, psychotic symptoms were more common in single patients, which is in line with the studies of Matsunaga et al. and Eisen et al. (18, 31). The same results have been reported about educational level, along with lower rate of positive family history in patients with psychotic symptoms (18).

Limitations and Suggestions: This study was not free of limitations. We examined a small number of patients from only one psychiatric clinic. Heterogeneity of subjects and lack of follow-up evaluation are other limitations in current study. Authors suggest further studies applied multi center with large number of patients and follow up system.

\section{CONCLUSION}

Our findings suggest that like mood disorders, OCD has a psychotic variant( $20.5 \%$ OCD patients ). The results also demonstrated that in patients with OCD, psychotic symptoms are more common in young, single, and less educated men, and those with more severe symptoms. In addition, these patients lack insight, and delusion is the most common psychotic symptom among them.

Conflict of Interests: The authors declare that they have no competing interests

Funding: None

Acknowledgments: The authors should appreciate all patients participated this study.

\section{REFERENCES}

1. Hofmeijer-Sevink MK, van Oppen $P$, van Megen $H J$, Batelaan NM, Cath DC, van der Wee NJ, et al. Clinical relevance of comorbidity in obsessive compulsive disorder: the Netherlands OCD Association study. Journal of affective disorders. 2013 Sep 25;150(3):847-54. PubMed PMID: 23597943. Epub 2013/04/20. eng.

2. Srivastava S, Bhatia MS, Thawani R, Jhanjee A. Quality of life in patients with obsessive compulsive disorder: A longitudinal study from India. Asian journal of psychiatry. 2011 Sep;4(3):178-82. PubMed PMID: 23051114. Epub 2012/10/12. eng.

3. Canals J, Hernandez-Martinez C, Cosi S, Voltas N. The epidemiology of obsessive--compulsive disorder in Spanish school children. Journal of anxiety disorders. 2012 Oct;26(7):746-52. PubMed PMID: 22858901. Epub 2012/08/04. eng.

4. Tumkaya S, Karadag F, Oguzhanoglu NK, Tekkanat C, Varma G, Ozdel O, et al. Schizophrenia with obsessivecompulsive disorder and obsessive-compulsive disorder with poor insight: a neuropsychological comparison. Psychiatry research. 2009 Jan 30;165(1-2):38-46. PubMed PMID: 18995914. Epub 2008/11/11. eng.

5. Rodriguez $\mathrm{Cl}$, Corcoran $\mathrm{C}$, Simpson HB. Diagnosis and treatment of a patient with both psychotic and obsessivecompulsive symptoms. The American journal of psychiatry. 2010;167(7):754-61. PubMed PMID: 20595428. eng.

6. Schirmbeck F, Zink M. Comorbid obsessive-compulsive symptoms in schizophrenia: contributions of pharmacological and genetic factors. Front Pharmacol. 2013;4:99-. PubMed PMID: 23950745. eng.

7. Hwang MY, Kim SW, Yum SY, Opler LA. Management of schizophrenia with obsessive-compulsive features. The Psychiatric clinics of North America. 2009 Dec;32(4):835-51. PubMed PMID: 19944887. Epub 2009/12/01. eng.

8. Attademo L, Bernardini F, Paolini E, Quartesan R. History and conceptual problems of the relationship between obsessions and hallucinations. Harvard review of psychiatry. 2015 Jan-Feb;23(1):19-27. PubMed PMID: 25563566. Epub 2015/01/08. eng.

9. Sarkhel S. Kaplan and Sadock's Synopsis of Psychiatry: Behavioral Sciences/Clinical Psychiatry, 10(th) edition. Indian Journal of Psychiatry. 2009 Oct-Dec;51(4):331-. PubMed PMID: PMC2802389. eng.

10. Sahoo P, Sethy RR, Ram D. Functional Impairment and Quality of Life in Patients with Obsessive Compulsive Disorder. Indian J Psychol Med. 2017 Nov-Dec;39(6):760-5. PubMed PMID: 29284808. eng.

11. Raines AM, Oglesby ME, Allan NP, Mathes BM, Sutton CA, Schmidt NB. Examining the role of sex differences in obsessive-compulsive symptom dimensions. Psychiatry research. 2018 Jan;259:265-9. PubMed PMID: 29091827. Epub 2017/11/02. eng.

12. Samiei M, Hedayati K, Mirabzadeh Ardekani A, Dolatshahi B, Daneshmand R, Samadi R. Obsessive-Compulsive Disorder in Hospitalized Patients with Schizophrenia. Basic and clinical neuroscience. 2016 Oct;7(4):323-30. PubMed PMID: 27872693. Pubmed Central PMCID: PMC5102561. Epub 2016/11/23. eng.

13. Adam Y, Meinlschmidt G, Gloster AT, Lieb R. Obsessivecompulsive disorder in the community: 12-month prevalence, comorbidity and impairment. Social psychiatry and psychiatric epidemiology. 2012 Mar;47(3):339-49. PubMed PMID: 21287144. Epub 2011/02/03. eng.

14. Raveendranathan D, Shiva L, Sharma E, Venkatasubramanian G, Rao MG, Varambally $S$, et al. Obsessive compulsive disorder masquerading as psychosis. Indian J Psychol Med. 2012;34(2):179-80. PubMed PMID: 23162197. eng. 
15. Sharifi V, Assadi SM, Mohammadi MR, Amini H, Kaviani $\mathrm{H}$, Semnani $\mathrm{Y}$, et al. A Persian translation of the Structured Clinical Interview for Diagnostic and Statistical Manual of Mental Disorders, Fourth Edition: psychometric properties. Comprehensive psychiatry. 2009 Jan-Feb;50(1):86-91. PubMed PMID: 19059520. Epub 2008/12/09. eng.

16. Namazi S, Baba MB, Halaliah Mokhtar H, Ghani Hamzah MS. Validation of the Iranian Version of the University of California at Los Angeles Posttraumatic Stress Disorder Index for DSM-IV-R. Trauma monthly. 2013;18(3):122-5. PubMed PMID: 24350169. Epub 10/14. eng.

17. Shooshtari MH, Davari-Ashtiani R, Shahrivar Z, Shabani A, Semnani $\mathrm{Y}$, Kaviani $\mathrm{H}$, et al. Structured clinical interview for DSM-IV (SCID Persian translation and cultural adaptation). Iranian journal of psychiatry. 2007:46-8.

18. Matsunaga $\mathrm{H}$, Kiriike $\mathrm{N}$, Matsui $\mathrm{T}$, Oya $\mathrm{K}$, Iwasaki $\mathrm{Y}$, Koshimune $\mathrm{K}$, et al. Obsessive-compulsive disorder with poor insight. Comprehensive psychiatry. 2002 MarApr;43(2):150-7. PubMed PMID: 11893994. Epub 2002/03/15. eng.

19. Bellino S, Patria L, Ziero S, Bogetto F. Clinical picture of obsessive-compulsive disorder with poor insight: a regression model. Psychiatry research. 2005 Sep 15;136(23):223-31. PubMed PMID: 16125785. Epub 2005/08/30. eng.

20. Solem S, Hagen K, Wenaas C, Haland AT, Launes G, Vogel $\mathrm{PA}$, et al. Psychotic and schizotypal symptoms in nonpsychotic patients with obsessive-compulsive disorder. BMC psychiatry. 2015 May 28;15:121. PubMed PMID: 26017268. Pubmed Central PMCID: PMC4446858. Epub 2015/05/29. eng.

21. Rosli ANM, Wan Ismail WS. Comorbidity of ObsessiveCompulsive Disorder and Schizophrenia in an Adolescent. Case Rep Psychiatry. 2015;2015:136835-. PubMed PMID: 26483984. Epub 09/21. eng.

22. Poyurovsky M, Fuchs C, Faragian S, Kriss V, Weisman G, Pashinian A, et al. Preferential aggregation of obsessivecompulsive spectrum disorders in schizophrenia patients with obsessive-compulsive disorder. Canadian journal of psychiatry Revue canadienne de psychiatrie. 2006 Oct:51(12):746-54. PubMed PMID: 17168249. Epub 2006/12/16. eng.

23. Gandhi P, Gadit AM. Delusion or obsession: clinical dilemma. BMC Res Notes. 2012;5:384-. PubMed PMID: 22838396. eng.

24. Oulis P, Konstantakopoulos G, Lykouras L, Michalopoulou PG. Differential diagnosis of obsessive-compulsive symptoms from delusions in schizophrenia: A phenomenological approach. World J Psychiatry. 2013;3(3):50-6. PubMed PMID: 24255875. eng.

25. Kozak MJ, Foa EB. Obsessions, overvalued ideas, and delusions in obsessive-compulsive disorder. Behaviour research and therapy. 1994 Mar;32(3):343-53. PubMed PMID: 8192634. Epub 1994/03/01. eng.

26. de Haan L, Dudek-Hodge C, Verhoeven Y, Denys D. Prevalence of psychotic disorders in patients with obsessivecompulsive disorder. CNS spectrums. 2009 Aug;14(8):4157. PubMed PMID: 19890235. Epub 2009/11/06. eng.

27. Sharma LP, Reddy YCJ. Obsessive-compulsive disorder comorbid with schizophrenia and bipolar disorder. Indian journal of psychiatry. 2019;61(Suppl 1):S140-S8. PubMed PMID: 30745688. eng.

28. Van Dael F, van Os J, de Graaf R, ten Have M, Krabbendam L, Myin-Germeys I. Can obsessions drive you mad? Longitudinal evidence that obsessive-compulsive symptoms worsen the outcome of early psychotic experiences. Acta psychiatrica Scandinavica. 2011 Feb;123(2):136-46. PubMed PMID: 20880068. Epub 2010/10/01. eng.

29. Poyurovsky M, Faragian S, Pashinian A, Heidrach L, Fuchs C, Weizman R, et al. Clinical characteristics of schizotypalrelated obsessive-compulsive disorder. Psychiatry research. 2008 May 30;159(1-2):254-8. PubMed PMID: 18378321. Epub 2008/04/02. eng.

30. O'Dwyer AM, Marks I. Obsessive-compulsive disorder and delusions revisited. The British journal of psychiatry : the journal of mental science. 2000 Mar;176:281-4. PubMed PMID: 10755077. Epub 2001/02/07. eng.

31. Eisen JL, Phillips KA, Rasmussen SA. Obsessions and delusions: The relationship between obsessive-compulsive disorder and the psychotic disorders. Psychiatric Annals. 1999;29(9):515-22.

32. Samiei M, Hedayati K, Mirabzadeh Ardekani A, Dolatshahi B, Daneshmand R, Samadi R. Obsessive-Compulsive Disorder in Hospitalized Patients with Schizophrenia. Basic and clinical neuroscience. 2016;7(4):323-30. PubMed PMID: 27872693. eng.

33. Guillem F, Satterthwaite J, Pampoulova T, Stip E. Relationship between psychotic and obsessive compulsive symptoms in schizophrenia. Schizophrenia research. 2009 Dec;115(2-3):358-62. PubMed PMID: 19560321. Epub 2009/06/30. eng.. 